\title{
Elevation of macrophage-derived chemokine in eosinophilic pneumonia : a role of alveolar macrophages
}

\author{
Kazuyoshi Manabe', Yasuhiko Nishioka', Jun Kishi', Mami Inayama', Yoshinori Aono', \\ Yoichi Nakamura ${ }^{2}$, Fumitaka Ogushi', Hiroyasu Bando ${ }^{3}$, Kenji Tani', and Saburo Sone ${ }^{1}$ \\ ${ }^{1}$ Department of Internal Medicine and Molecular Therapeutics, Institute of Health Biosciences, The \\ University of Tokushima Graduate School, Tokushima, Japan ; ${ }^{2}$ Clinical Research Center for Allergy \\ and Rheumatology, National Kochi Hospital, Kochi, Japan ; and ${ }^{3}$ Department of Pulmonary Medicine, \\ Tokushima Prefectural Central Hospital, Tokushima, Japan
}

\begin{abstract}
Macrophage-derived chemokine (MDC/CCL22) and thymus-and activation-regulated chemokine (TARC/CCL17) are ligands for CC chemokine receptor 4. Recently, TARC has been reported to play a role in the pathogenesis of idiopathic eosinophilic pneumonia (IEP). The purpose of this study was to evaluate the role of MDC in IEP and other interstitial lung diseases (ILDs). MDC and TARC in the bronchoalveolar lavage fluid (BALF) were measured by enzymelinked immunosorbent assay in patients with ILDs and healthy volunteers (HV). We also examined the expression of MDC mRNA in alveolar macrophages (AM) by real-time quantitative reverse transcriptase-polymerase chain reaction. Both MDC and TARC were detected only in BALF obtained from IEP patients. The concentration of MDC was higher than that of TARC in all cases. The level of MDC in IEP correlated with that of TARC. AM from IEP patients expressed a significantly higher amount of MDC than that from $\mathrm{HV}$ at the levels of protein and mRNA. MDC in BALF from IEP dramatically decreased when patients achieved remission. These findings suggest that MDC, in addition to TARC, might be involved in the pathogenesis of IEP, and AM play a role in the elevation of MDC in IEP. J. Med. Invest. 52 : 85-92, February, 2005
\end{abstract}

Keywords : bronchoalveolar lavage fluid, macrophage-derived chemokine, thymus-and activation-regulated chemokine, eosinophilic pneumonia, alveolar macrophages, interstitial lung diseases

\section{INTRODUCTION}

Idiopathic eosinophilic pneumonia (IEP) is characterized by the accumulation of eosinophils in the alveolar spaces and the interstitium of the lung with unknown etiology, frequently accompanied by peripheral eosinophilia $(1,2)$. Previous studies have demonstrated that eosinophils play a critical role in the lung injury of IEP by releasing toxic granule proteins including major

Received for publication November 30, 2004 ; accepted Jaunary 7, 2005.

Address correspondence and reprint requests to Saburo Sone, M.D., Department of Internal Medicine and Molecular Therapeutics, Institute of Health Biosciences, The University of Tokushima Graduate School, Kuramoto-cho, Tokushima 770-8503, Japan and Fax : +81-88-633-2134. basic protein (MBP), eosinophilic cationic protein (ECP) and eosinophil peroxidase (EPO) $(2,3)$. However, the pathogenesis of IEP still remains unclear.

Much attention has focused on the mechanisms involved in the accumulation of eosinophils in the lung. Since interleukin (IL)-5 has the capacity to attract and activate eosinophils $(4,5)$, it has been considered to play a role in the recruitment of eosinophils to the site of inflammation in the lung of IEP patients. In fact, IL-5 has been reported to be elevated in bronchoalveolar lavage fluid (BALF) of IEP patients $(6,7)$. Furthermore, eotaxin, a selective $\mathrm{CC}$ chemokine for eosinophils, has been demonstrated to be essential for the accumulation of eosinophils in the lung using an allergic inflammation model $(8,9)$. Recent reports demonstrated that eotaxin 
was also elevated in BALF of IEP $(10,11)$. These results suggested that IL-5 and eotaxin might play a critical role in the recruitment of eosinophils in the lung of IEP patients.

Recently, $\mathrm{CD} 4^{+} \mathrm{T}$ lymphocytes were divided into two subgroups on the basis of their cytokine production. T helper (Th) 1 cells produce IL-2, interferon (IFN)- $\gamma$ and tumor necrosis factor (TNF) $-\beta$ and mediate cellular immune responses, whereas Th2 cells secrete IL-4, IL-5 and IL-6 and promote the humoral immune responses (12). The chemokine receptors specifically expressed on Th1or Th2 cells were also identified, and it was found that Th1 cells are recognized by the expression of CCR5 or CXCR3, and Th2 cells by CCR4 (13). Although Th1/Th2 balance in IEP is still unclear, it is likely that Th2 cells play a role in the pathogenesis of IEP since IL-5 was elevated in BALF of IEP. Recently, Miyazaki et al. reported that thymus-and activationregulated chemokine (TARC), which is a ligand for the CCR4 chemokine receptor, contributed the recruitment of Th2 lymphocytes to the lung in patients with IEP(14).

In the present study, we examined the level of macrophage-derived chemokine (MDC), which is another ligand for the CCR4 chemokine receptor, in BALF from patients with IEP or other interstitial lung diseases (ILDs). Furthermore, we examined the production of MDC by alveolar macrophages (AM) derived from BALF of patients with IEP.

\section{MATERIALS AND METHODS}

\section{Subjects}

Studies were performed in 18 patients with IEP, 8 patients with idiopathic pulmonary fibrosis (IPF), 8 patients with cryptogenic organizing pneumonia (COP)/bronchiolitis obliterance organizing pneumonia (BOOP), 8 patients with sarcoidosis, 8 patients with hypersensitivity pneumonitis (HP) and 7 healthy volunteers (HV) (table 1). IEP was diagnosed by clinical criteria as follows : 1) no known cause of EP such as drug allergy or parasitic and fungal infections ; 2) alveolar, interstitial or mixed opacity on chest roentgenograms;3) an increased number of eosinophils in BALF and the alveolar spaces and septa by transbronchial lung biopsy (TBLB) ; 4) prompt resolution with or without corticosteroid therapy (1). IPF was diagnosed according to the International Consensus Statement (15). The diagnosis of $\mathrm{COP} / \mathrm{BOOP}$ was based on clinicopathological evaluation as follows ; 1) subacute onset; 2) alveolar opacity on chest roentgenogram and CT ;3) no evi- dence of infectious or collagen vascular diseases which might cause $\mathrm{COP}$;4) typical histologic pattern by TBLB; 5) rapid responses to corticosteroid therapy (15). Sarcoidosis was diagnosed by previously described clinical and histologic criteria (16). The diagnosis of HP was performed on the basis of the previously described criteria (17).

None of the patients were receiving corticosteroid therapy at the time of the investigation. Two patients with IEP had a past history of symptomatic bronchial asthma (BA), whereas none of the patients with other ILDs and healthy volunteers had atopic status. Three IEP patients received a second BAL after clinical remission with or without corticosteroid therapy.

\section{Bronchoalveolar lavage}

The study was performed under the ethical guideline of the University of Tokushima and the written informed consent was obtained from the subjects. BAL was performed as described previously (18). Briefly, a flexible fiberoptic bronchoscope (Model 1T20 ; Olympus Co., Tokyo, Japan) was wedged into a segmental or subsegmental bronchus of the middle lobe or lingual, and lavage was performed with a total volume of $150 \mathrm{ml}$ of sterile $0.9 \%$ saline warmed at $37^{\circ} \mathrm{C}$ in three $50-\mathrm{ml}$ aliquots. The lavage fluid was gently aspirated by syringe after deep inspiration. The fluid recovered was passed through a sterile gauze and centrifuged at $250 \mathrm{x}$ g for $10 \mathrm{~min}$ at $4^{\circ} \mathrm{C}$ to precipitate cells, and the supernatants were stored at $-70^{\circ} \mathrm{C}$ until examination. The total number of cells was counted using the trypanblue dye exclusion test. Differential counts on 400 cells were carried out on smears of sedimented cells stained with Diff-Quik stain (Baxter Dade AG, Duedingen, Switzerland) (19).

\section{Measurement of MDC and TARC}

The frozen BALF was quickly thawed and used to examine the concentration of MDC and TARC by ELSA (R\&D system, Minneapolis, MN, USA). The procedure was performed as described in the manufacturer's instructions (20). The minimal detectable level of MDC and TARC was 62.5 and $7 \mathrm{pg} / \mathrm{ml}$, respectively.

\section{Harvesting of the supernatant of AM}

The total cells in BALF were added to a 96-well flatbottom plate at $1 \times 10^{5} \mathrm{AM}$ per well. After incubation at $37^{\circ} \mathrm{C}$ for $1 \mathrm{~h}$, these cells were washed three times with cold phosphate-buffered saline (PBS) (-) to remove the non-adherent cells. The purity of AM at this point was more than $90 \%$, as judged by the staining with DiffQuik stain. AM were subsequently cultured in RPMI 
1640 supplemented with $10 \%$ heat-inactivated fetal bovine serum (FBS ; GIBCO, Grand Island, NY, USA). Their supernatants were harvested after culture for 24 and 48 hrs.

\section{Preparation of total RNA of AM}

Total RNA was isolated from AM using Isogen (Wako K.K., Kyoto, Japan). Briefly, BAL cells were added to a $10 \mathrm{~cm}$-dish with RPMI 1640 supplemented with 10\% FBS. After incubation at $37^{\circ} \mathrm{C}$ for $1 \mathrm{~h}$, these cells were washed three times with cold PBS (-) to remove the non-adherent cells. One milliliter of Isogen was added to the remaining cells, and then the cells were harvested using a cell-scraper (SUMITOMO BAKELITE CO., LTD., Tokyo, Japan) to an eppendorf tube. Total RNA was extracted according to the manufacturer's instructions (21).

\section{Real-time quantitative PCR analysis for MDC}

Ten nanograms of total RNA was used for RT-PCR using a One step real-time PCR Kit (Applied Biosystems, Foster City, CA, USA). Real-time quantitative PCR was performed in the ABI prism 7700 Sequence detector (Applied Biosystems). The primer and probe for human $\mathrm{MDC}$ were designed based on the published sequence data (22), and are as follows : MDC forward primer, 5'-TGCCGTGATTACGTCCGTTAC-3'; MDC reverse primer, 5'-ATCGGCACAGATCTCCTTATCC3'; MDC TaqMan probe, 5'-FAM-CGCGTGGTGA AACACTTCTACTGGACCTC-TAMRA-3'. Each RTPCR reaction was performed in duplicate wells using a TaqMan One-step RT-PCR Master Mix Reagents Kit (Applied Biosystems). The RT reaction was performed at $48^{\circ} \mathrm{C}$ for $30 \mathrm{~min}$ and $95^{\circ} \mathrm{C}$ for $10 \mathrm{~min}$. PCR was performed for $40 \mathrm{cycles}$ at $95^{\circ} \mathrm{C}$ for $15 \mathrm{sec}$ and $60^{\circ} \mathrm{C}$ for 1 min. Real-time RT-PCR for $\beta$-actin was also performed as a control using a TaqMan $\beta$-actin Control Reagents (Applied Biosystems) under the same conditions as for MDC. The relative expression of MDC mRNA was calculated as the value of MDC mRNA/the value of $\beta$-actin.

\section{Statistical analysis}

Statistical analysis was performed using the unpaired two-tailed Student's $t$ test. Correlation coefficients were determined using the Pearson's linear regression analysis. Statistical analysis was performed with StatView software. Differences were considered significant when $p$ values were less than 0.05 .

\section{RESULTS}

Characteristics of BALF of patients with various ILDs

The characteristics of BALF of patients with various ILDs are shown in Table 1. The total number of cells in BALF of patients with IEP, sarcoidosis and HP was significantly higher than that of HV. The percentage of lymphocytes was significantly increased in the COP, sarcoidosis and HP groups, and that of eosinophils was higher in IEP and COP when compared with HV.

The concentration of MDC and TARC in BALF of patients with various ILDs

We examined the level of MDC and TARC in BALF of patients with various ILDs using ELISA. The results are shown in figure 1. MDC in BALF was detected in thirteen of eighteen IEP patients (72\%) (Fig. 1a). TARC was also detected in nine of eighteen IEP patients (50\%) (Fig. 1b). However, neither MDC nor TARC was de-

Table 1. Characteristics of study populations

\begin{tabular}{|c|c|c|c|c|c|c|c|}
\hline \multirow[b]{3}{*}{ Group } & \multirow[b]{3}{*}{ male/female } & \multirow[b]{3}{*}{ Age (yr) } & \multicolumn{5}{|c|}{ Bronchoalveolar lavage } \\
\hline & & & \multirow{2}{*}{$\begin{array}{l}\text { Total cells } \\
\left(\times 10^{5} / \mathrm{ml}\right)\end{array}$} & \multicolumn{4}{|c|}{ Percentages of total cells } \\
\hline & & & & $\mathrm{AM}$ & Ly & Neut & Eo \\
\hline IEP & $9 / 9$ & $48.0 \pm 4.2$ & $10.1 \pm 2.3^{*}$ & $25.9 \pm 3.8^{\#}$ & $21.1 \pm 5.3$ & $3.2 \pm 1.4$ & $49.8 \pm 5.7^{\#}$ \\
\hline IPF & $7 / 1$ & $67.1 \pm 1.7$ & $3.2 \pm 1.0$ & $66.4 \pm 8.3^{\dagger}$ & $21.3 \pm 4.7$ & $5.8 \pm 3.1$ & $6.5 \pm 3.1$ \\
\hline $\mathrm{COP}$ & $3 / 5$ & $51.7 \pm 5.1$ & $6.2 \pm 2.3$ & $50.7 \pm 6.9^{\#}$ & $41.5 \pm 7.0^{*}$ & $3.4 \pm 1.7$ & $4.4 \pm 1.3^{\dagger}$ \\
\hline SAR & $3 / 5$ & $47.0 \pm 4.9$ & $3.9 \pm 0.6^{\dagger}$ & $48.3 \pm 6.5^{\#}$ & $50.6 \pm 6.6^{\#}$ & $0.7 \pm 0.3$ & $0.6 \pm 0.3$ \\
\hline $\mathrm{HP}$ & $4 / 4$ & $54.4 \pm 3.1$ & $9.2 \pm 2.0^{\S}$ & $39.3 \pm 7.8^{\#}$ & $56.0 \pm 8.4^{\#}$ & $1.5 \pm 0.5$ & $3.3 \pm 1.5$ \\
\hline $\mathrm{HV}$ & $6 / 1$ & $21.9 \pm 0.8$ & $2.0 \pm 0.2$ & $88.9 \pm 2.6$ & $10.0 \pm 2.5$ & $0.7 \pm 0.2$ & $0.3 \pm 0.2$ \\
\hline
\end{tabular}

Data are shown as Mean \pm SEM. ${ }^{*} P<0.005$, compared with the group of $\mathrm{HV}$; ${ }^{\#} P<0.001$, compared with the group of $\mathrm{HV}$;

${ }^{\dagger} P<0.05$, compared with the group of $\mathrm{HV} ;{ }^{\S} P<0.01$, compared with the group of HV. AM : alveolar macrophages ; COP : cryptogenic organizing pneumonia ; Eo : eosinophils ; IEP : idiopathic eosinophilic pneumonia ; HP : hypersensitivity pneumonitis ; HV : healthy volunteers ; IPF : idiopathic pulmonary fibrosis ; Ly : lymphocytes ; Neut : neutrophils ; SAR : sarcoidosis. 
tected in BALF of HV or patients with other ILDs including IPF, COP, sarcoidosis and HP. In three patients in the IEP group who were complicated with symptomatic BA, one patient did not show an elevation of either MDC or TARC.

a)

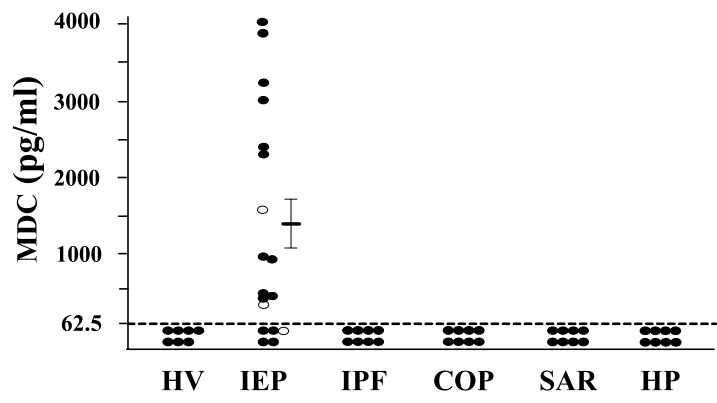

b)

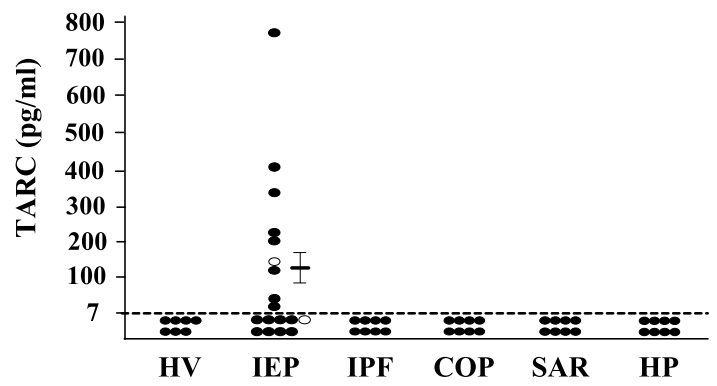

Fig. 1. Concentration of macrophage-derived chemokine (MDC) and thymus- and activation-regulated chemokine (TARC) in bronchoalveolar lavage fluid (BALF). The BALF obtained from healthy volunteers (HV) or patients with various interstitial lung diseases was used for the measurement of a) MDC ; and b) TARC with ELISA. Each closed circle indicates an individual specimen and open circles are the data from symptomatic asthmatic patients. Bars are mean \pm SEM of all values. A value of 62.5 or $7 \mathrm{pg} / \mathrm{ml}$ was given to all samples that read out below the level of detection in the ELISA for MDC or TARC, respectively. COP : cryptogenic organizing pneumonia, IEP : idiopathic eosinophilic pneumonia, HP: hypersensitivity pneumonitis, IPF : idiopathic pulmonary fibrosis, SAR : sarcoidosis. a)

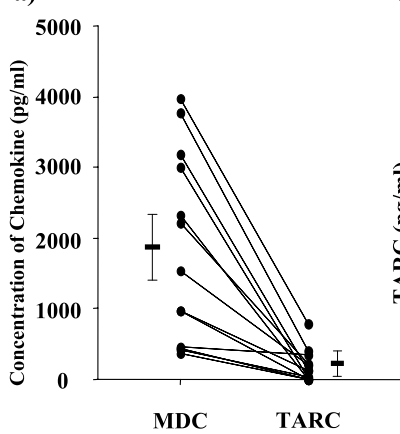

b)

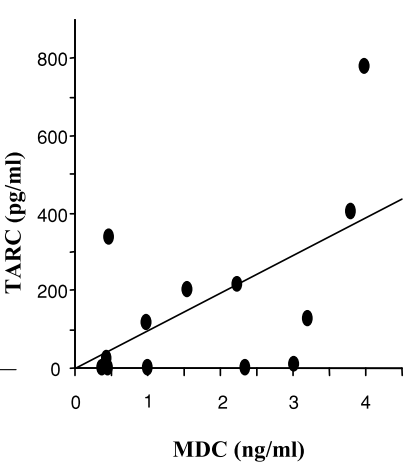

Fig. 2. Correlation between the level of macrophage-derived chemokine (MDC) and thymus-and activation-regulated chemokine (TARC) in patients with idiopathic eosinophilic pneumonia (IEP). a) Comparison of the level of MDC and TARC in patients with IEP. Each closed circle indicates an individual patient. Bars are mean \pm SEM of all values $(n=13)$. The level of MDC was significantly higher than that of TARC $(p<0.001)$; b) Correlation between the level of MDC and TARC in patients with IEP. The level of MDC correlated with that of TARC $(\mathrm{r}=0.62, p<0.05)$. A value of $7 \mathrm{pg} / \mathrm{ml}$ was given to all samples that read out below the level of detection in the ELISA for TARC.
Comparison of the level of MDC and TARC in BALF of patients with IEP

We next compared the level of MDC and TARC in BALF of patients with IEP. As shown in Fig. 2a, the concentration of MDC was significantly higher than that of TARC (Mean \pm SEM ; $1819 \pm 371$ versus $176 \pm$ $63 \mathrm{pg} / \mathrm{ml}, \mathrm{p}<0.001)$. In all patients, MDC was consistently higher than TARC. On the other hand, the level

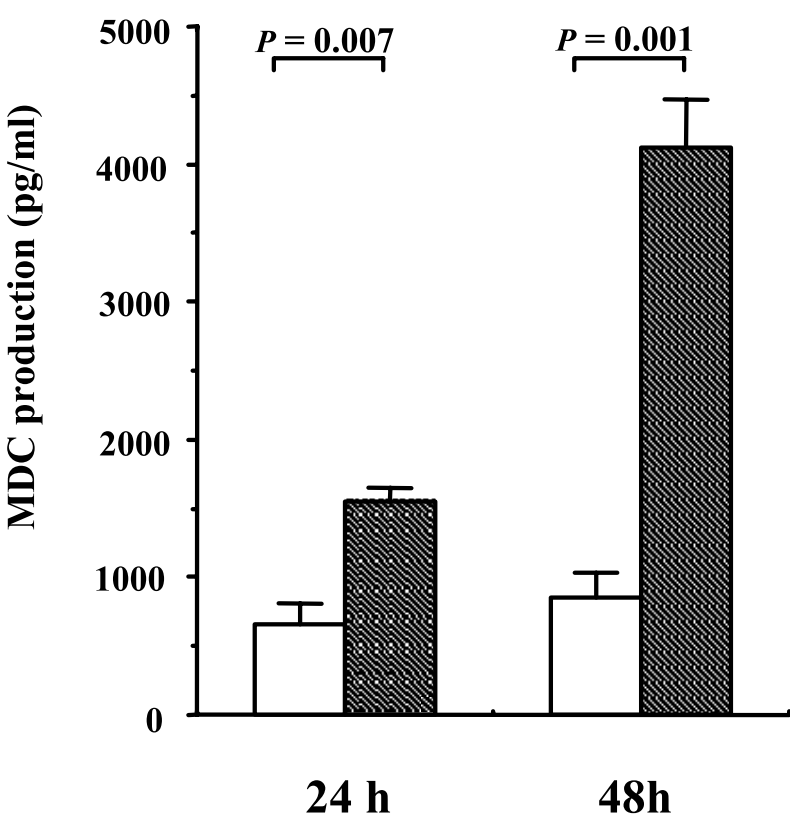

Fig. 3. Production of macrophage-derived chemokine (MDC) by alveolar macrophages (AM) harvested from healthy volunteers (HV) or patients with idiopathic eosinophilic pneumonia (IEP). AM were cultured without stimulation for 24 and $48 \mathrm{hrs}$. The supernatants were harvested, and the concentration of MDC was measured with ELISA. Data are shown as mean \pm SD of three HV (open column) or patients with IEP (shaded column).

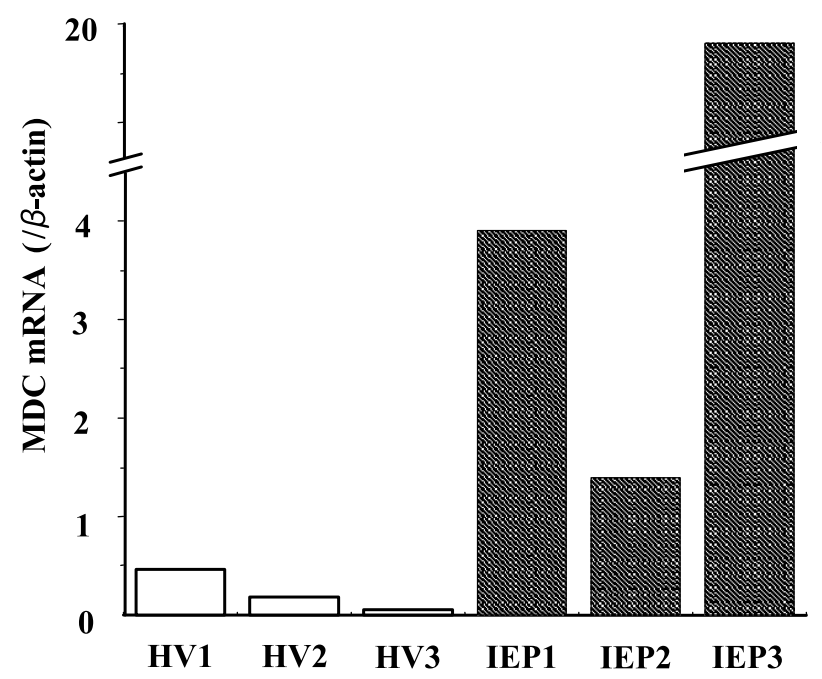

Fig. 4. Expression of mRNA of macrophage-derived chemokine (MDC) in alveolar macrophages (AM) from patients with idiopathic eosinophilic pneumonia (IEP). Total RNA was extracted from AM in healthy volunteers (HV) or patients with IEP. The real-time quantitative RT-PCR for MDC was performed as described in Methods. Each column indicates the data from an individual subject. 
Table 2. Decreased level of macrophage-derived chemokine in bronchoalveolar lavage fluid from patients with idiopathic eosinophilic pneumonia after clinical remission*

\begin{tabular}{|c|c|c|c|c|c|}
\hline \multirow[b]{2}{*}{ Case } & \multirow[b]{2}{*}{ Clinical status } & \multicolumn{4}{|c|}{ Bronchoalveolar lavage } \\
\hline & & $\begin{array}{l}\text { Total cells } \\
\text { (x 105/ml) }\end{array}$ & $\begin{array}{c}\text { Eosinophils } \\
(\%)\end{array}$ & $\begin{array}{c}\mathrm{MDC} \\
(\mathrm{pg} / \mathrm{ml})\end{array}$ & $\begin{array}{l}\text { TARC } \\
(\mathrm{pg} / \mathrm{ml})\end{array}$ \\
\hline \multirow[t]{2}{*}{1} & active & 4.2 & 36.8 & 2999 & 13.5 \\
\hline & remission & 2.1 & 2.0 & 72 & $<7$ \\
\hline \multirow[t]{2}{*}{2} & active & 37.5 & 89.2 & 2325 & $<7$ \\
\hline & remission & 5.9 & 3.6 & $<62.5$ & $<7$ \\
\hline \multirow[t]{2}{*}{3} & active & 7.6 & 45.0 & 3973 & 785 \\
\hline & remission & 6.1 & 16.0 & $<62.5$ & $<7$ \\
\hline
\end{tabular}

${ }^{*}$ Case 1 and 3 were treated by oral administration with $0.5 \mathrm{mg} / \mathrm{kg}$ of prednisolone for one month and then corticosteroids were tapered. When the pulmonary infiltrates on chest radiographs improved, a second BAL was performed. Case 2 showed spontaneous improvement. This patient also received a second BAL after clinical remission. MDC: macrophage-derived chemokine, TARC : thymus-and activation-regulated chemokine.

of MDC in BALF of patients with IEP correlated with that of TARC $(r=0.62, p<0.05)$ (Fig. 2b). We also analyzed the correlation between the level of MDC or TARC and the number of lymphocytes or eosinophils in BALF, and found that there was no correlation between these factors (data not shown).

\section{Increased production of MDC by AM from patients with IEP}

Recently, Fahy et al. reported that human AM harvested from asthmatic patients could produce MDC (23). We therefore examined the production of MDC by AM harvested from $\mathrm{HV}$ and patients with IEP. AM harvested from IEP had the ability to spontaneously produce a higher amount of MDC when compared with that of HV (Fig. 3). Furthermore, we analyzed the expression of MDC mRNA using a real-time quantitative RT-PCR. As shown in Fig. 4, AM from three patients with IEP also expressed a higher amount of MDC transcript at the mRNA level when compared with that of HV.

\section{Clinical relevance of $M D C$ level in BALF of patients with IEP}

Three patients with active IEP received a second BAL when the clinical symptoms and signs of active IEP improved spontaneously or after a therapy with corticosteroids. The level of MDC or TARC in BALF declined in parallel with a reduction in the number of total cells and eosinophils in BALF (Table 2).

\section{DISCUSSION}

In the present study, we demonstrated that the con- centrations of MDC and TARC in BALF of patients with IEP were significantly higher than those of $\mathrm{HV}$ or patients with other ILDs. Furthermore, when the production of MDC by AM at the protein and mRNA levels was examined, AM harvested from patients with IEP showed the higher production of MDC than HV.

Recently, Miyazaki et al. reported that TARC in BALF of patients with EP was significantly higher than that of HV or patients with other ILDs such as HP, sarcoidosis and IPF (14). MDC recognizes CCR4, a receptor that is shared by TARC (24). Therefore, it could be of importance to examine whether MDC or TARC plays a more critical role in the pathogenesis of IEP. In the present study, we demonstrated that MDC as well as TARC was elevated in BALF of patients with IEP. These data are consistent with the results recently reported by Katoh et al., in which they demonstrated that both MDC and TARC were elevated in BALF of IEP (25). They also reported that the concentrations of MDC and TARC were correlated with CCR4 ${ }^{+}$T cells in BALF of patients with IEP. However, they did not examine COP and HP patients, and the source of MDC in the lung of IEP. Therefore, we further analyzed the MDC level in BALF of patients with various ILDs and the production of MDC by AM in IEP.

The level of MDC was significantly higher than that of TARC in all IEP patients. These data, together with a report that the chemotactic activity of MDC for CCR4-positive cells was higher than that of TARC at the same concentration (24), strongly suggest that MDC, in addition to TARC, could be a major chemoattractant for Th2-type cells in the lung of IEP. However, MDC-producing cells are different from those that produce TARC in the lung ; the former being macrophages and the latter endothelial and bronchial epithelial cells $(27,28)$. In fact, when we 
examined the production of TARC from AM, the level of TARC in the supernatant was undetectable or negligible in all cases (data not shown). These results were consistent with the previous reports showing that both murine and human macrophages did not express TARC even at the mRNA level $(29,30)$. On the other hand, we observed a positive correlation between the MDC and TARC level in BALF of patients with IEP, implying that the production and function of these chemokines is likely to be cooperatively regulated. Furthermore, both MDC and TARC were rapidly reduced when the disease activity of IEP was improved. These data suggests that both MDC and TARC were strictly related to the clinical status of IEP.

The major source of MDC is reported to be monocytederived macrophages and dendritic cells (28). However, it has been unknown whether human tissue macrophages could produce MDC. Fahy et al. recently reported that human AM harvested from asthmatic patients could produce MDC in response to diesel exhaust particle (DEP) (23). They also demonstrated that AM produced a significant amount of MDC without any stimulation, although they did not compare MDC production of AM with healthy controls. In the present study, we first reported that the spontaneous production of MDC from patients with IEP was significantly higher than that of $\mathrm{HV}$, strongly indicating that AM in IEP were stimulated by unknown stimuli to induce MDC production in vivo. However, there is a possibility that other cells in the lung play a role in the increased level of MDC in BALF of patients with IEP. In particular, DCs would be candidate for MDC producer cells since they have a much higher ability to produce MDC, although the number of DCs in the lung is much less (28). Accordingly, our results suggest that MDC produced by AM could be involved in the pathogenesis of IEP, although the possibility that DCs play a role in MDC production in the lung still remains.

On the other hand, we did not detect any correlation between the level of MDC or TARC and the number of lymphocytes and eosinophils. Although Bochner et al. reported that $\mathrm{MDC}$ also had the direct chemotactic activity on eosinophils (31), the activity of MDC or TARC in the recruitment of eosinophils to the lung is presumably due to the indirect effects of secondary factors which might be produced by $\mathrm{Th} 2$ lymphocytes attracted and activated by MDC. In fact, IL-5, which is known to be produced by Th2 cells, is directly involved in the recruitment of eosinophils in the lung (5).

In summary, MDC as well as TARC was significantly elevated in BALF of patients with IEP. AM in IEP patients could produce a higher amount of $\mathrm{MDC}$ when compared with HV. These results suggest that AM play a crucial role in Th2-type immune response in the pathogenesis of IEP via enhanced MDC production.

\section{ACKNOWLEDGEMENTS}

This work was supported by Grant-in-Aid for scientific research by the Ministry of Education, Science, Sports and Culture, Japan.

The authors would like to thank Drs. Masahiko Azuma, Junya Miyata, Mari Miki and Soji Kakiuchi for their technical assistance.

\section{REFERENCES}

1. Allen JN, Davis WB : Eosinophilic lung diseases. Am J Respir Crit Care Med 150:1423-1438, 1994

2. Albera $\mathrm{C}$, Ghio $\mathrm{P}$ : Eosinophils in eosinophilic pneumonia. Eur Respir J 9 : 2437-2439, 1996

3. Davis WB, Fells GA, Sun XH, Gadek JE, Venet A, Crystal RG : Eosinophil-mediated injury to lung parenchymal cells and interstitial matrix : a possible role for eosinophils in chronic inflammatory disorders of the lower respiratory tract. J Clin Invest 74 : 269-278, 1984

4. Lopez AF, Sanderson CJ, Gamble JR, Campbell HD, Young IG, Vadas MA : Recombinant human interleukin 5 is a selective activator of human eosinophil function. J Exp Med 167:219-224, 1988

5. Wang JM, Rambaldi A, Biondi A, Chen ZG, Sanderson CJ, Mantovani A : Recombinant human interleukin 5 is a selective eosinophil chemoattractant. Eur J Immunol 19 : 701-705, 1989

6. Walker C, Bauer W, Braun RK, Menz G, Braun P, Schwarz F, Hansel TT, Villiger B : Activated T cells and cytokines in bronchoalveolar lavages from patients with various lung diseases associated with eosinophils. Am J Respir Crit Care Med 150 : 1038-1048, 1994

7. Taniguchi H, Katoh S, Kadota J, Matsubara Y, Fukushima K, Mukae H, Matsukura S, Kohno S: Interleukin 5 and granulocyte-macrophage colony stimulating factor levels in bronchoalveolar lavage fluid in interstitial lung disease. Eur Respir J 16 : 959-964, 2000

8. Jose PJ, Griffiths-Johnson DA, Collins PD, Walsh DT, Moqbel R, Totty NF, Truong O, Hsuan JJ, Williams TJ : Eotaxin : a potent eosinophil chemoattractant cytokine detected in a guinea pig model of allergic airway inflammation. J Exp Med 179: 
881-887, 1994

9. Ganzalo JA, Jia GQ, Aguirre V, Friend D, Coyle AJ, Jenkins NA, Lin GS, Katz H, Lichtman A, Copeland N, Kopf M : Mouse eotaxin expression parallels eosinophil accumulation during lung allergic inflammation but it is not restricted to a Th2-type response. Immunity $4: 1-4,1996$

10. Katoh S, Matsumoto N, Fukushima K, Mukae H, Kadota J, Kohno S, Matsukura S : Elevated chemokine level in bronchoalveolar lavage fluid of patients with eosinophilic pneumonia. J Allergy Clin Immunol 106 : 730-736, 2000

11. Tateno $H$, Nakamura $H$, Minematsu $N$, Amakawa $K$, Terashima T, Fujishima S, Luster AD, Lilly CM, Yamaguchi K : Eotaxin and monocyte chemoatractant protein-1 in chronic eosinophilic pneumonia. Eur Respir J 17 : 962-968, 2001

12. Mosmann TR, Coffman RL: TH1 and TH2 cells : different patterns of lymphokine secretion lead to different functional properties. Ann Rev Immunol 7 : 145-173, 1987

13. Bonecchi R, Bianchi G, Bordignon PP, D'Ambrosio D, Lang R, Borsatti A, Sozzani S, Allavena P, Gray PA., Mantovani A, Sinigaglia F:Differential expression of chemokine receptors and chemotactic responsiveness of type $1 \mathrm{~T}$ helper cells (Th1s) and Th2s. J Exp Med 187 : 129-134, 1998.

14. Miyazaki E, Nureki S, Fukami T, Shigenaga T, Ando M, Ito K, Ando H, Sugisaki K, Kumamoto T, Tsuda T: Elevated levels of thymus-and activationregulated chemokine in bronchoalveolar lavage fluid from patients with eosinophilic pneumonia. Am J Respir Crit Care Med 165:1125-1131, 2002

15. American Thoracic Society : Idiopathic pulmonary fibrosis : Diagnosis and treatment. International consensus statement. American Thoracic Society (ATS), and European Respiratory Society. Am J Respir Crit Care Med 157 : 199-203, 1998

16. American Thoracic Society : Statement on Sarcoidosis. This joint statement of the American thoracic society (ATS), the European respiratory society (ERS) and the world association of sarcoidosis and other granulomatous diaorders (WASOG) was adopted by the ATS board of directors and by the ERS executive committee. Am J Respir Crit Care Med 160 : 736-755, 1999

17. Bourke SJ, Dalphin JC, Boyd G, McSharry C, Baldwin CI, Calvert JE : Hypersensitivity pneumonitis :currunt concepts. Eur Respir J18:81s92s, 2001

18. Tani K, Ogushi F, Huang L, Kawano T, Tada H, Hariguchi N, Sone S : CD13/aminopeptidase N, a novel chemoattractant for $\mathrm{T}$ lymphocytes in pulmonary sarcoidosis. Am J Respir Crit Care Med $161: 1636-1642,2000$

19. Azuma M, Nakamura Y, Sano T, Okano Y, Sone $\mathrm{S}$ :Adhesion molecule expression on eosinophils in idiopathic eosinophilic pneumonia. Eur Respir J $9: 2494-2500,1996$

20. Nishioka Y, Yano S, Fujiki F, Mukaida N, Matsushima K, Sone S : Combined therapy of multidrug-resistant human lung cancer with antiP-glycoprotein antibody and monocyte chemoattractant protein-1gene transduction: the possibility of immunological overcoming of multidrug resistance. Int J Cancer 71 : 170-177, 1997

21. Endo K, Ogushi F, Kawano T, Sone S: Comparison of the regulations by Th2-type cytokines of the arachidonic acid metabolic pathway in human alveolar macrophages and monocytes. Am J Respir Cell Mol Biol 19 : 300-307, 1998

22. Godiska R, Chantry D, Raport CJ, Sozzani S, Allavena P, Leviten D, Mantovani A, Gray PW : Human macrophage-derived chemokine (MDC), a novel chemoattractant for monocytes, monocytederived dendritic cells, and natural killer cells. J Exp Med 185 : 1595-1604, 1997

23. Fahy O, Sénéchal S, Pène J, Scherpereel A, Lassalle P, Tonnel AB, Yessel H, Wallaert B, Tsicopoulos A:Diesel exposure favors Th2 cell recruitment by mononuclear cells and alveolar macrophages from allergic patients by differentially regulating macrophage-derived chemokine and IFN- $\gamma$-induced protein-10 production. J Immunol 168: 5912-5919, 2002

24. Imai T, Chantry D, Raport CJ, Woods CL, Niahimura M, Godiska R, Yosie O, Gray PW : Macrophagederived chemokine is a functional ligand for the CC chemokine receptor 4. J Biol Chem 273 : 17641768, 1998

25. Katoh S, Fukushima K, Matsumoto N, Matsumoto K, Abe K, Onai N, Matsushima K, Matsukura S : Accumulation of CCR4-expressing CD4+T cells and high concentration of its ligands (TARC and MDC) in bronchoalveolar lavage fluid of patients with eosinophilic pneumonia. Allergy 58 : 518523, 2003

26. Struyf S, Proost P, Sozzani S, Mantovani A, Wuyts A, Clercq ED, Schols D, Van Damme J : Enhanced anti-HIV-1 activity and altered chemotactic potency of NH2-terminally processed macrophage-derived chemokine (MDC) imply an additional MDC receptor. J Immunol 161 : 2672-2675, 1998

27. Berin MC, Eckmann L, Broide DH, Kagnoff MF : 
Regulated production of the Thelper 2-type T-cell chemoattractant TARC by human bronchial epithelial cells in vitro and in human lung xenografts. Am J Respir Cell Mol Biol 24 : 382-389, 2001

28. Vulcano M, Albanesi C, Stoppacciaro A, Bagnati R, D’Amico G, Struyf S, Transidico P, Bonecchi R, Del Prete A, Allavena P, Ruco LP, Chiabrando C, Girolomoni G, Mantovani A, Sozzani S: Dendritic cells as a major source of macrophage-derived chemokine/CCL22 in vitro and in vivo. Eur J Immunol 31 : 812-822, 2001

29. Lieberam I, Förster I : The murine $\beta$-chemokine TARC is expressed by subsets of dendritic cells and attracts primed $\mathrm{CD} 4^{+}$T cells. Eur J Immunol 29 : 2684-2694, 1999

30. Hashimoto S, Suzuki T, Dong HY, Nagai S, Yamazaki $\mathrm{N}$, Matsushima K: Serial analysis of gene expression in human monocyte-derived dendritic cells. Blood 94 : 845-852, 1999

31. Ochner BS, Bickel CA, Taylor ML, MacGlashan DW Jr, Gray PW, Raport CJ, Godiska R:Macrophagederived chemokine induces human eosinophil chemotaxis in a $\mathrm{CC}$ chemokine receptor 3 -and $\mathrm{CC}$ chemokine receptor 4-independent manner. J Allergy Clin Immunol 103 : 527-532, 1999 